\title{
Adaptive Modeling and Operation Optimization for the Cold End System of Thermal Power Units based on Mechanism and Statistical Analysis
}

\author{
Wei Jin ${ }^{1}$, Shaojun Ren ${ }^{1}$, Yunshan Dong ${ }^{1}$, Fengqi Si ${ }^{1 *}$, Ce Wang ${ }^{2}$, Zhenwei Zhang ${ }^{3}$ \\ ${ }^{1}$ key laboratory of energy thermal conversion and its process measurement and control, ministry of education, Southeast University, \\ Nanjing 210096, China \\ ${ }^{2}$ Zhejiang zheneng taizhou second power generation co., LTD., Taizhou 318000, China \\ ${ }^{3}$ Zhejiang zheneng technology research institute co., LTD., Hangzhou 310026, China
}

\begin{abstract}
The operation optimization for the cold end system is an efficient means to improve the economy of steam turbine units. To compensate for the inadequacy of the traditional mechanism analysis utilized in obtaining actual operating characteristics of the cold end system, the prediction model of the exhaust pressure was established on the basis of mechanism analysis combined with data from the operation process. An online adaptive updating strategy was introduced to guarantee the modeling accuracy. A discrete model of the cooling tower outlet water temperature (CTOWT) was constructed based on the operation data partitioned into different groups according to the pump operating mode change (POMC). Combining the above two models, the coupled model of the cold end system was therefore obtained. A model-based operation optimization system was then implemented for the cold end system in a coal-fired power plant. Experimental trials authenticate that the optimization suggestions provided by the system can effectively enhance the benefit of power generation.
\end{abstract}

\section{Introduction}

In recent decades, with large-scale renewable energy connected to the power grid, coal-fired power plants more frequently run in cycling load operation mode to compensate for the intermittency of renewable energy [1]. As a significant auxiliary system of steam turbine, the cold end system has direct impact on the economic operating of the units when the load varies in a wide range. Note that for every $1 \mathrm{kPa}$ decrease in the back pressure, the steam turbine output will increase $(1 \%-2 \%)[2]$, whereas the reduction of the back pressure is at the expense of extra power consumption of the circulating pumps. It is estimated that the circulating water pumps consume about (1\%-1.5\%) of the total power of the plant[3].

There has been quite a bit of attention attracted on the cold end system modeling methods and operation optimization strategies[4-6]. Li et al.[7] applied the least square support vector machine algorithm (LSSVM) to modify the deviation of operation data and the results obtained from mechanism equations. However, it is worth noting that the exhaust pressure is essentially different from the condenser pressure. Research shows that the uneven flow field distribution in the complicated exhaust passage seriously affects the thermal performance of the condenser[8]. In terms of cooling tower modeling, CFD (computational fluid dynamics) models were employed to investigate cooling tower characteristics[9-11], which were generally computational expensive. Recently, data-driven approaches have been gaining increasingly popularity in modeling the cooling tower. Considering the operation data within the same operating mode have the similar characteristics, Pan et al.[12] developed a set of local linear models on the basis of data portioned into several groups by the fuzzy c-mean clustering algorithm. Similarly, Wang et al.[13] proposed a dimensionless index to describe the cooling capability of a cooling tower.

In this paper, the implementation of operation optimization is founded on the conception of evaluating the impact of a specific pump combination change on the cold end system. In view of this, a discrete model of CTOWT is therefore constructed with the data partitioned by different pump operating mode changing way. An adaptive update strategy is introduced to correspond with the actual process. Thereafter, the prediction model of exhaust pressure is further established on the basis of mechanism model of with least squares support vector machine (LSSVM) algorithm. Embedded with the coupled model, a cold end optimization system is developed to provide guidance for the actual operation.

\section{Overview of the system background}

Structure schematic diagram of the studied cold end system shared by two turbo-generator units is depicted in figure1. On the premise of safety, the circulating water 
system generally operates in the following five modes: two units with two pumps (P2), three pumps (P3), four pumps (P4), five pumps (P5) and six pumps (P6). The research aims to investigate which pump operating mode under a certain condition can simultaneously fulfil the requirements of safety and economy.

\section{Modeling of the cold end system}

\subsection{Modeling of steam exhaust pressure}

\subsubsection{Thermodynamic characteristic model of the condenser.}

An adaptive heat transfer coefficient updating strategy is considered to enhance the accuracy of the model. The thermodynamic characteristic model of the condenser is shown in figure 2.

The energy balance equation of the process is expressed as follows:

$$
k A_{c} \Delta t_{m}=D_{w} C_{p}\left(t_{w 2}-t_{w 1}\right)
$$

Equation (2) calculates the logarithmic mean temperature difference:

$$
\Delta t_{m}=\frac{\Delta t_{\max }-\Delta t_{\min }}{\ln \frac{\Delta t_{\max }}{\Delta t_{\min }}}=\frac{\left(t_{s}-t_{w 1}\right)-\left(t_{s}-t_{w 2}\right)}{\ln \frac{t_{s}-t_{w 1}}{t_{s}-t_{w 2}}}=\frac{t_{w 2}-t_{w 1}}{\ln \frac{t_{s}-t_{w 1}}{t_{s}-t_{w 2}}}
$$

Combining equations (1) and (2), the OHTC can be obtained as follows:

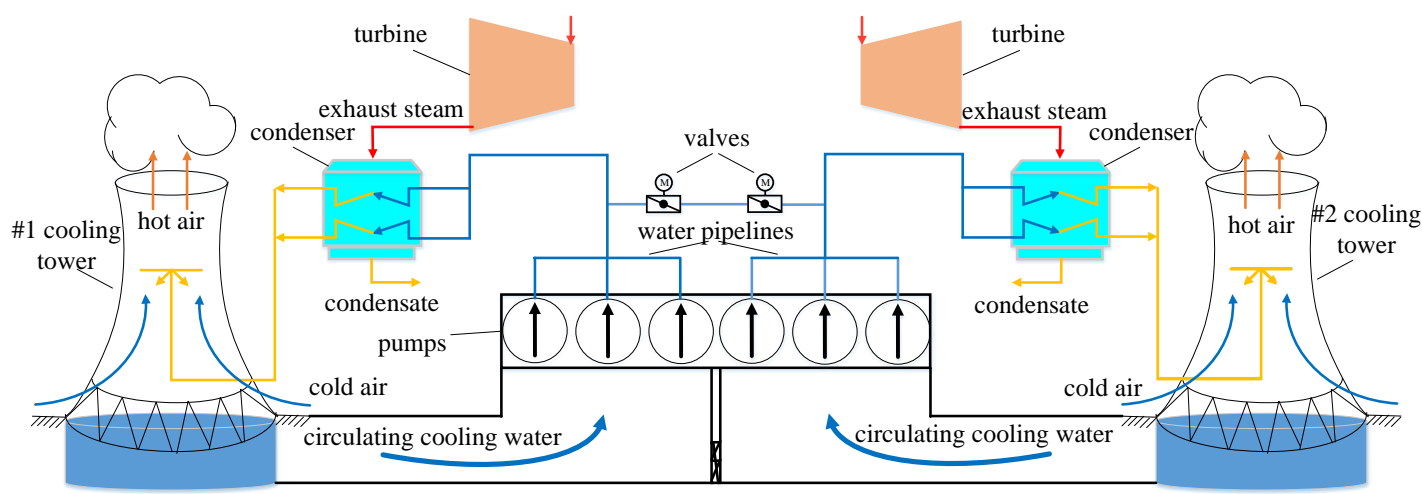

Fig. 1. Diagram of the cold end system in a coal-fired power station.

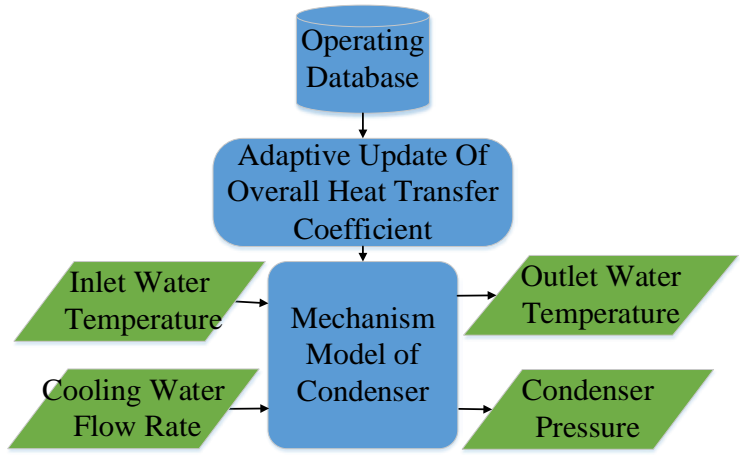

Fig. 2. Thermal characteristic model of condenser.

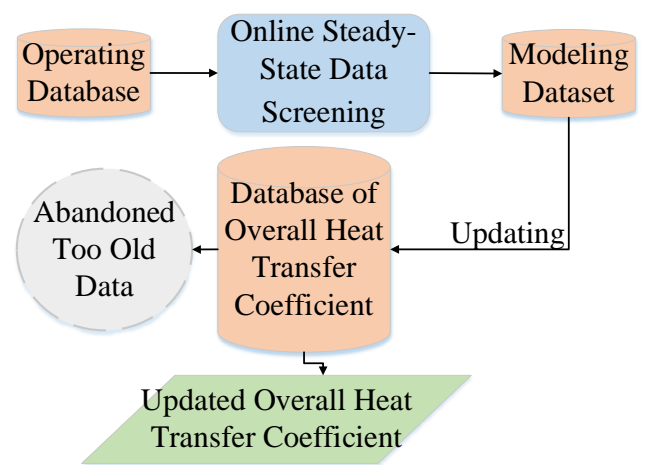

Fig. 3. Adaptive updating logic diagram of overall heat transfer coefficient.

$$
k=\frac{D_{w} C_{p}}{A_{c}} \ln \frac{t_{s}-t_{w 1}}{t_{s}-t_{w 2}}
$$

The Antoine equation utilized to calculate the saturated vapour pressure is presented below:

$$
\ln p_{c}=a-\frac{b}{t_{s}+c}
$$

Thus, the saturation temperature can be inversely derived from equation (4):

$$
t_{s}=\frac{3826.36}{9.3876-\ln p_{c}}-227.68
$$

Note that the range applicable to the saturation temperature is $17^{\circ} \mathrm{C}$ to $227^{\circ} \mathrm{C}$ [15].

With equations (3) and (5), the overall heat transfer coefficient of the condenser is presented as follows:

$$
k=\frac{D_{w} C_{p}}{A_{c}} \ln \frac{\frac{3826.36}{9.3876-\ln p_{c}}-227.68-t_{w 1}}{\frac{3826.36}{9.3876-\ln p_{c}}-227.68-t_{w 2}}
$$

The update logic diagram is depicted in figure 3 . Based on the latest $\mathrm{N} k$ values in the database, the overall heat transfer coefficient utilized to calculate the thermal characteristics of the condenser can be obtained as follows: 


$$
K=\sum_{i=1}^{N} \mu_{i} k_{i}
$$

The terminal temperature difference is expressed as equation (8):

$$
\delta t=\frac{\Delta t_{w}}{\exp \left(K A_{c} / 1000 C_{p} D_{w}\right)-1}
$$

From equation (1) to equation (8), the condensation temperature of steam in the condenser can be attained:

$$
t_{\mathrm{s}}=t_{\mathrm{w} 1}+\Delta t_{w}+\delta t
$$

The condenser pressure can be obtained from the following empirical formula:

$$
p_{\mathrm{c}}=\left(\frac{t_{\mathrm{s}}+100}{57.66}\right)^{7.46} \times 9.806 \times 10^{-6}(\mathrm{MPa})
$$

The temperature of circulating water at the outlet of the condenser is as follows:

$$
t_{\mathrm{w} 2}=t_{\mathrm{w} 1}+\Delta t
$$

From equation (1) to equation (11), the calculation model of condenser outlet water temperature and pressure is established:

$$
\begin{gathered}
t_{\mathrm{w} 2}=f_{t}\left(D_{\mathrm{c}}, t_{\mathrm{w} 1}, D_{\mathrm{w}}\right) \\
p_{\mathrm{c}}=f_{p_{\mathrm{c}}}\left(D_{\mathrm{c}}, t_{\mathrm{w} 1}, D_{\mathrm{w}}\right)
\end{gathered}
$$

Table 1. Error statistics of the CTOWT model.

\begin{tabular}{ccccc}
\hline \multirow{2}{*}{ Error } & \multicolumn{2}{c}{$\# 1$ cooling tower } & \multicolumn{2}{c}{ \#2 cooling tower } \\
\cline { 2 - 5 } & $\begin{array}{c}\text { Absolute } \\
\text { error } /{ }^{\circ} \mathrm{C}\end{array}$ & $\begin{array}{c}\text { Relative } \\
\text { error } / \%\end{array}$ & Absolute error $/{ }^{\circ} \mathrm{C}$ & Relative error $/ \%$ \\
\hline Max & 1.280 & 5.006 & 1.311 & 5.977 \\
Min & 0.003 & 0.000 & 0.000 & 0.000 \\
Mean & 0.325 & 1.884 & 0.338 & 1.513 \\
Standard deviation & 0.237 & 0.014 & 0.244 & 0.013 \\
\hline
\end{tabular}

\subsubsection{Deviation modification based on LSSVM.}

Numerous investigations revealed that the aerodynamic performance of exhaust passage is influenced by multi factors like inlet swirl distribution[14], steam wetness[15], non-uniformity flow field distribution[16]. The major operating parameters such as load, condenser inlet water temperature, exhaust flow and condenser pressure. were reasonably selected as the input of the data-driven model, and LSSVM algorithm was then applied to establish the deviation modification model.

\subsection{Modeling of the cooling tower}

An analysis program was developed in-house to capture start-stop action happening time of circulating water pumps by scanning historical data. Once the action captured, working conditions of a certain POMC are recorded subsequently and hence the POMC dataset are generated, namely, $D_{1}, D_{2} \cdots D_{n}$. Each subset $D_{i}$ consists of data that categorized by one specific pump operating mode changing way.

Imbedded with statistical analysis conducted on POMC dataset in the previous section, LSSVM algorithm was utilized to fit the relationship between the variation of CTOWT with the load, and the ambient parameters under different POMC, namely:

$$
\Delta t_{2}=f_{\mathrm{ct}}(N, t, u, p, A, B)
$$

Thus, the CTOWT can be calculated as follows:

$$
t_{2,2}=t_{2,1}+\Delta t_{2}
$$

\subsection{Coupling model of the cold end system}

$$
t_{\mathrm{w} 2}=t_{1}, t_{\mathrm{w} 1}=t_{2}
$$

According to equation (16), the models of exhaust pressure and the cooling tower are coupled together to predict the exhaust pressure when the pump operation mode switches between different operation modes under given load and environmental factors, that is:

$$
p_{t}=f\left(N, D_{c}, t, u, p, D_{w}, t_{2}, A, B\right)
$$

The calculation flow chart of the exhaust steam pressure is presented in figure 4.

\subsection{Model validation}

The $2 \times 1050$ MWe coal-fired power plant is in Taizhou, China. Figure 5, figure 6 and table 2 present the accuracy of the cooling tower models. Figure 7 and table 2 present the accuracy of the coupled model. The average relative error is about $1.7 \%$, indicating high consistency between the model and the actual process. Hence, the model of exhaust pressure can be reasonably further applied to the operation optimization. 


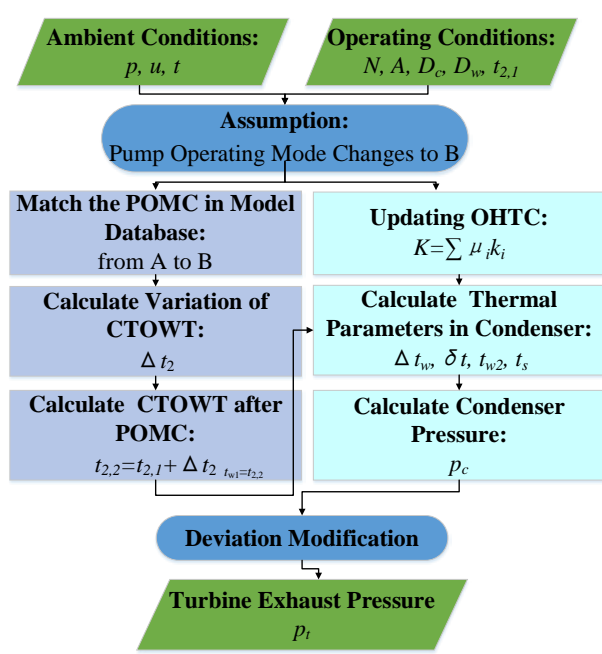

Fig. 4. Calculation flow chart of cold end system model

Table 2. Error statistics of steam turbine exhaust pressure model.

\begin{tabular}{ccc}
\hline \multirow{2}{*}{ Error } & \multicolumn{2}{c}{ Steam turbine exhaust pressure } \\
\cline { 2 - 3 } & Absolute error $/ \mathrm{kPa}$ & Relative error $/ \%$ \\
\hline Max & 0.358 & 4.986 \\
Min & 0.000 & 0.002 \\
Mean & 0.141 & 1.727 \\
Standard deviation & 0.079 & 0.998 \\
\hline
\end{tabular}

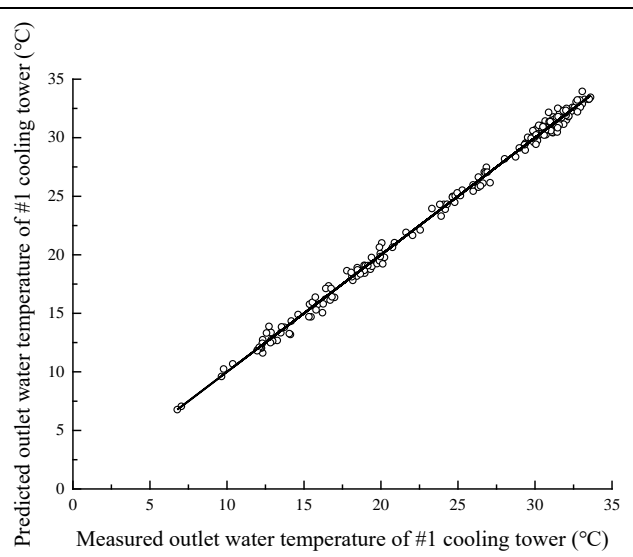

Fig. 5. Comparison between measured and predicted \#1 CTOWT

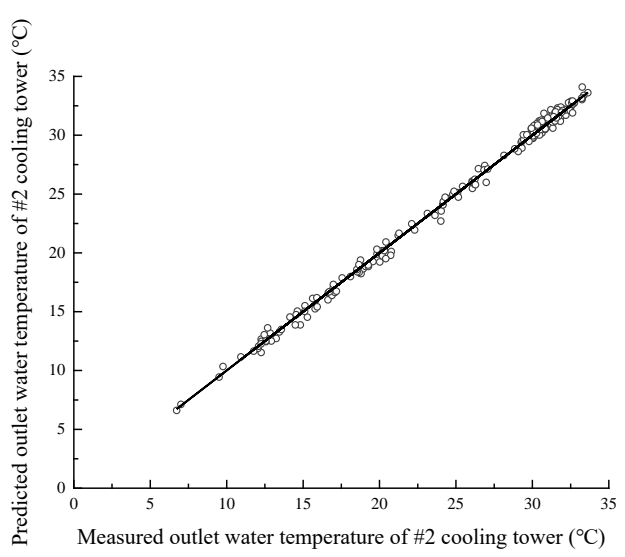

Fig. 6. Comparison between the measured and predicted \#2 CTOWT

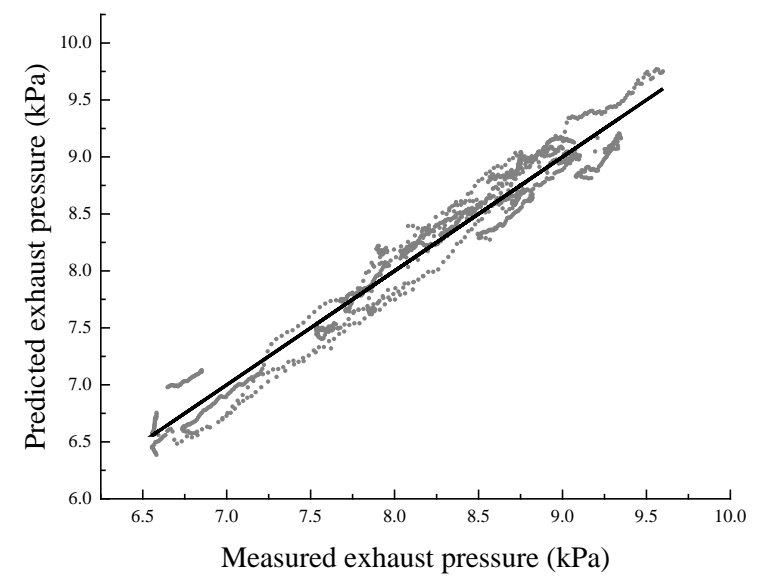

Fig. 7. Comparison between the actual and predicted exhaust pressure

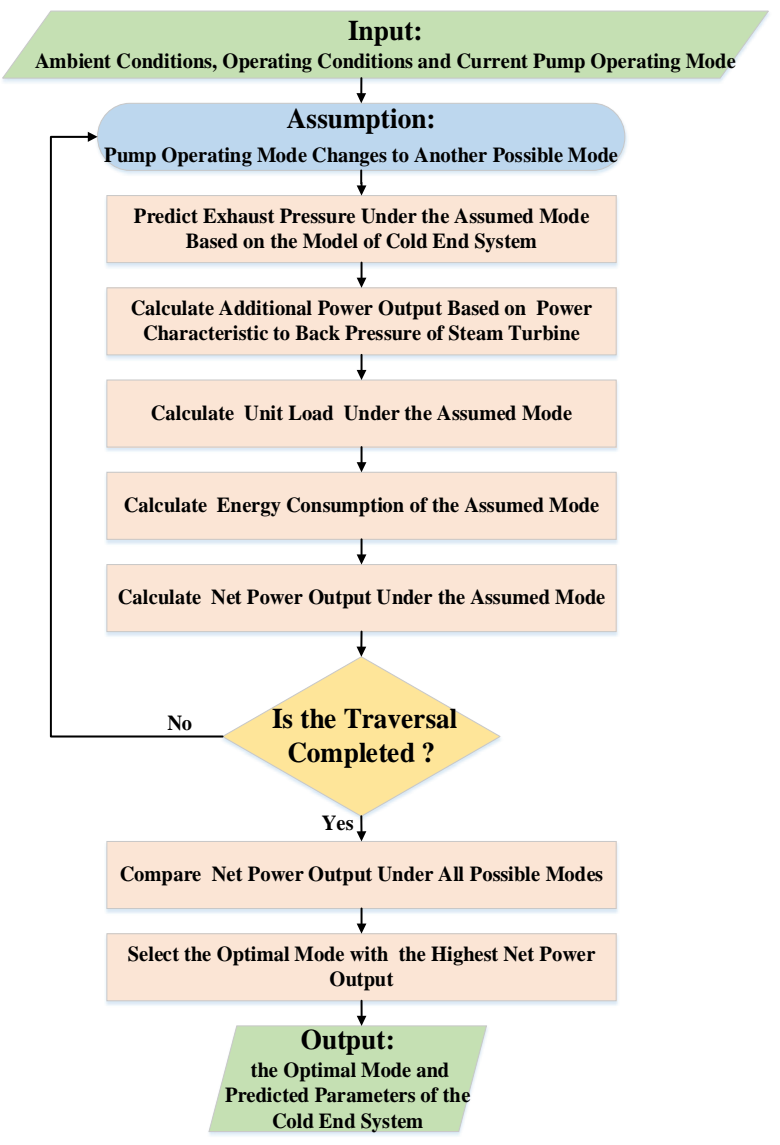

Fig. 8. Flow chart of the operation optimization for the cold end system 
Table 3. Economic indexes of the whole plant after a specific POMC

\begin{tabular}{ccccc}
\hline POMC & Net power/kW & $\begin{array}{c}\text { Variation of } \\
\text { auxiliary power } \\
\text { consumption } / \mathbf{\%}\end{array}$ & $\begin{array}{c}\text { Variation of heat } \\
\text { consumption } /(\mathbf{k J} /(\mathbf{k W} \cdot \mathbf{h}))\end{array}$ & $\begin{array}{c}\text { Variation of coal } \\
\text { consumption } /(\mathbf{g} /(\mathbf{k W} \cdot \mathbf{h}))\end{array}$ \\
\hline From P6 to P5 & $\mathbf{2 3 4 1}$ & $-\mathbf{0 . 2 1 5}$ & $\mathbf{- 1 . 2 2 4}$ & $-\mathbf{0 . 1 4 5}$ \\
From P6 to P4 & 1440 & -0.899 & 26.594 & -0.089 \\
From P6 to P3 & -2796 & -1.347 & 63.806 & 0.173 \\
From P6 to P2 & -40548 & -1.801 & 262.756 & 2.509 \\
\hline
\end{tabular}

\section{Optimization strategy and implementation}

Figure 8 presents the optimization process. Take a pump operating mode change at 13:30 on August 3, 2018 as an example. Before the switch, the loads of unit \#1 and unit \#2 were 800MW and 815MW, respectively. The pump operating mode was set at P6, and the ambient temperature was $34^{\circ} \mathrm{C}$, the humidity $63 \%$. At the moment, the cold end optimization system suggested the operating mode of P5 based on the embedded model. Following the recommendation, the on-duty operator stopped a pump and the parameters of the cold end reached a stable state after about 35 minutes. Table 3 summarizes the economic indexes of the whole plant after a possible pump operation mode change under such circumstance. Compared with five running pumps, the increased output power of the turbines is little to offset the more energy consumption under the operating mode of six pumps.

\section{Conclusion}

(1) The exhaust pressure was no longer considered equivalent to the condenser pressure but the result further modified with LSSVM algorithm on the basis of condenser pressure. Forgetting factors were introduced in modeling the condenser pressure as an adaptive update strategy of the overall heat transfer coefficient. The mean relative error is within $2 \%$ for the exhaust pressure model.

(2) A discrete model of the cooling tower outlet water temperature was established based on the data partitioned into different groups according to the pump operating mode changing way. The prediction accuracy and calculating speed revealed that the proposed modeling approach could fulfill the requirements of field application.

(3) A cold end optimization system was developed based on the adaptive model. The reliability and capability of the implemented system were demonstrated in experimental trials. The whole work offers a practical opportunity for the operators to conserve energy in the operation of the cold end system.

\section{References}

1. Batalla-bejerano J and Trujillo-baute E 2016 Impacts of intermittent renewable generation on electricity system costs Energy Policy 94 411-20
2. Li S, He D, Chen G and Li H 2010 Analysis on features of power plant cold-end system and optimization J. Therm. Sci. Technol. 9 36-42

3. Hang X, Zhao L, An Y and Chang J 2004 A discrete optimized model for the monobloc configured circulating water system of a thermal power plant and its applications J. Eng. Therm. ENERGY POWER 19 302-6

4. Zheng L K, Chen C, Xie D M and Zhang H L 2013 Optimization of the Cold-End System of the 1000MW Ultra-Supercritical Units by VB $A d v$. Mater. Res. 694-697 778-81

5. Chen C, Xie D, Xiong Y and Zhang H 2014 Optimization of turbine cold-end system based on BP neural network and genetic algorithm Front. Energy 8 459-463

6. Yang J and Zhang R 2017 Optimization for steam turbine cold-end system of a nuclear power plant and sensitivity analysis J. Nucl. Eng. Radiat. Sci. 3 2016-9

7. LI P, WANG P, ZHOU J, WANG $X$ and SI F 2018 Circulating Water System Operation Optimization of Cogeneration Units Based on Adaptive Model Proc. CSEE 38 5500-9

8. Liu J 1998 The calculation of asymmetric flow in turbine exhaust systems (University of Cambridge)

9. Dang Z, Zhang Z, Gao M and He S 2019 Numerical simulation of thermal performance for super large-scale wet cooling tower equipped with an axial fan Int. J. Heat Mass Transf. 135 220-34

10. Ma H, Si F, Kong Y, Zhu K and Yan W 2015 A new theoretical method for predicating the part-load performance of natural draft dry cooling towers Appl. Therm. Eng. 91 1106-15

11. Ma H, Si F, Li L, Yan W and Zhu K 2015 Effects of ambient temperature and crosswind on thermo-flow performance of the tower under energy balance of the indirect dry cooling system Appl. Therm. Eng. 78 90-100

12. Pan T, Shieh S, Jang S, Tseng W, Wu C and Ou J 2011 Statistical multi-model approach for performance assessment of cooling tower Energy Convers. Manag. 52 1377-85

13. Wang J-G, Shieh S-S, Jang S-S and Wu C-W 2013 Discrete model-based operation of cooling tower based on statistical analysis Energy Convers. Manag. 73 226-33

14. Fu J and Liu J 2008 Influences of inflow condition 
on non-axisymmetric flows in turbine exhaust hoods J. Therm. Sci. 17 305-13

15. Jiang X, Lin A, Malik A, Chang X and Xu Y 2019 Numerical investigation on aerodynamic characteristics of exhaust passage with consideration of multi-factor components in a supercritical steam turbine Appl. Therm. Eng. 162
114085

16. Fu J, Liu J and Zhou S 2007 Experimental and numerical investigation of interaction between turbine stage and exhaust hood Proc. Inst. Mech. Eng. Part A J. Power Energy 221 991-9

\section{Nomenclature}

$k \quad$ overall heat transfer coefficient, $\mathrm{kJ} /\left(\mathrm{m}^{2} \cdot \mathrm{h} \cdot \mathrm{K}\right)$

$\Delta p_{t} \quad$ deviation between the exhaust pressure and

$A_{c} \quad$ outside surface of tube bundles, $\mathrm{m}^{2}$

$\Delta t_{m} \quad$ logarithmic mean temperature difference, $\mathrm{K}$

$D_{c} \quad$ condensate mass flow rate, $\mathrm{t} / \mathrm{h}$

$D_{w} \quad$ circulating water flow rate, $\mathrm{t} / \mathrm{h}$

$C_{p} \quad$ specific heat capacity of water, $\mathrm{kJ} /(\mathrm{kg} \cdot \mathrm{K})$

$t_{w 1} \quad$ inlet water temperature of condenser, $\mathrm{K}$

$t_{w 2} \quad$ outlet water temperature of condenser, $\mathrm{K}$

$t_{s} \quad$ condensation temperature of exhaust steam, $\mathrm{K}$

$p_{c} \quad$ condenser pressure, $\mathrm{MPa}$

$K$ updated overall heat transfer coefficient, $\mathrm{kJ} /\left(\mathrm{m}^{2} \cdot \mathrm{h} \cdot \mathrm{K}\right)$

$\delta t \quad$ terminal temperature difference of condenser, $\mathrm{K}$

$\Delta t_{w} \quad$ tem

$t_{1} \quad$ inlet water temperature of cooling tower, $\mathrm{K}$

$t_{2} \quad$ outlet water temperature of cooling tower, $\mathrm{K}$

$N \quad$ load, MW

$t \quad$ dry bulb temperature, $\mathrm{K}$

$u \quad$ relative humidity, \%

p atmospheric pressure, $\mathrm{kPa}$

$\Delta t_{2} \quad$ outlet water temperature variation of cooling tower after pump operating mode change, $\mathrm{K}$

A pump operating mode before change

$B$ pump operating mode after change

$t_{2,1} \quad$ outlet water temperature of cooling tower before

2,1 pump operating mode change, $\mathrm{K}$

$t_{2,2}$ outlet water temperature of cooling tower after

2,2 pump operating mode change, $\mathrm{K}$

$D$ dataset
$\Delta N_{n} \quad$ net power of the units, $\mathrm{kW}$
$\Delta N_{t} \quad$ turbine additional power after pump operating
$\Delta N_{p} \quad$ increased energy consumption of pumps after pump operating mode change, $\mathrm{kW}$

\section{Subscripts}

A pump operating mode before change

$B$ pump operating mode after change

w circulating water

c condenser

s saturation state

m mean

$t \quad$ turbine

$p \quad$ pump

Abbreviations

CTOWT cooling tower outlet water temperature

POMC pump operating mode change

LSSVM the least square support vector machine algorithm

CTIWT cooling tower inlet water temperature

OHTC overall heat transfer coefficient

EP exhaust pressure

CP condenser pressure

Greek symbols

$\mu \quad$ forgetting factor 